\title{
Title: Youth blogging and serious illness
}

Corresponding author: Assistant professor Linda Nesby, Department of Culture and

Literature, UiT The Arctic University of Norway, P.O. Box 6050 Langnes, 9037,

linda.nesby@uit.no, (47) 47627895

Co-author: Senior researcher Anita Salamonsen, Department of Community Medicine, The

National Research Center in Complementary and Alternative Medicine (NAFKAM), UiT The Arctic University of Norway, Norway.

Key words: pathographies, youth, blogging, intercommunication, empowerment

Published in Med Humanities 2016;42:46-51 doi:10.1136/medhum-2015-010723 
ABSTRACT: In recent years, a growing number of young people who experience illness tend to blog about it. In this paper, we question whether and how illness blogs illustrate the intercommunicative aspect of blogging by bringing forth both the literary concept of the implied reader and the sociological concepts of empowerment and agency in the analysis. We argue that young people blogging about serious illness demonstrate the inherent intercommunicative potential of blogging. We also argue that youth blogging about serious illness may represent a fruitful strategy for ill young people to create meaning, stay frontstage in youth communities and build self-esteem and confidence out of chaos. Furthermore, we argue that these blogs may contribute rather unique experience-based knowledge and reflections about existential issues to other young blog readers who may otherwise not get access to this aspect of life. Youth blogging about serious illness thereby reflects a patient group so far not very visible, and through the genre youth stand out as more competent when it comes to illness and healthcare issues than what is often presumed.

\section{Youth blogging and serious illness}

The depiction of illness and death is one of the most frequent themes within literature. In The Book of Job, for instance, human suffering is the key issue and William Shakespeare's knowledge of medicine left frequent traces in his dramas. ${ }^{1}$ An example is the depiction of an epileptic fit that strikes Julius Caesar in the drama carrying the same name:

when the fit was on him, I did mark

How he did shake: 'tis true, this god did shake;

His coward lips did from their colour fly,

And this same eye whose bend doth awe the world

Did lose his lustre: I did hear him groan. ${ }^{2}$ 
The themes of illness and death have also entered the Internet. In modern times, illness along with the frequent process of recovery retains a social and cultural aspect: "A growing body of literature has recognized that the Internet has become a significant space for the recovery work that accompanies the diagnosis of serious illness $[\ldots]{ }^{3} .{ }^{3}$ Especially young people embrace the Internet as a medium for rendering their experience of illness and maintaining their social life during illness.

Over the last decade, "blogging" has become a popular platform for communicating and sharing private thoughts about a diverse specter of themes where fashion, physical exercise and food are perhaps some of the most recognized. The word "blog" was introduced in 1997 referring to "frequently-updated, chronologically-ordered, author-driven websites with the capability of reader feedback." ${ }^{4}$ In this article, we will focus on the increasing importance of illness blogs written by young people. A growing number of young people, especially girls who experience illness tend to blog about it, and such blogs often have many followers. In this paper, the question we will put forward is whether and how illness blogs illustrate the intercommunicative aspect of blogging by bringing forth both the literary concept of the implied reader and the sociological concepts of empowerment and agency in the analysis.

\section{BLOGS}

Blogs vary in form and content. When it comes to form, the succinct "Frequency, Brevity, and Personality" provides a summary of pivotal formal traits. ${ }^{5}$ There are blogs about almost everything. Yet it is possible to make some general comments about blogs, and Herring and colleagues have identified three primary categories, namely individually authored personal journals, "filters" (blogs that select and provide commentary on information from other websites) and "knowledge" blogs. The majority of blogs, according to Herring's study, were 
personal journals. Indeed, the term "blog" seems to be synonymous with the online journal form. ${ }^{6}$ The dimension of privacy, however, varies according to the blog's main theme, where an illness blog appears more private than a fashion blog.

An illness blog is defined by Meriam-Webster online dictionary as a site "[...] that contains an online personal journal with reflections, comments and often hyperlinks provided by the writer. Illness blogs are used to express the experience of illness and to connect with readers via the Internet". ${ }^{7}$ Blogging is a form of autobiographical writing often compared with writing a diary. ${ }^{8}$ The intriguing question, then, is why blog in public when writing a traditional diary is considered exclusively private? An answer may be that these two forms of illness expressions are radically different. Whereas the diary is not an intercommunicative tool, blogs are. The possibility (for the readers) of leaving comments is perhaps the most significant trait of blogs and inherent in every definition of "blog" or "blogging". Schmidt (2007) describes how blogs through comments and references to other online sources in the postings, as well as through links to favorite blogs in the sidebar (the "blogroll”), form clustered networks of interconnected texts: the "blogosphere". ${ }^{9}$ However, the author of the blog retains ownership of, and ultimate control over, the blog's content, and the relation between the author and the reader is thus asymmetrical. ${ }^{10}$ Perhaps blogs are more like radio shows than they are like diaries, aiming at a broad audience, and open to, but yet not based on (necessarily expecting) public response. ${ }^{11}$

\section{THE ILLNESS BLOGS OF ALICE PYNE AND REGINE STOKKE}

There are thousands of illness blogs online. We decided to analyze the blogs of the young girls Alice Pyne and Regine Stokke. These blogs have in common an active use of the blog genres' intercommunicative aspect, while they are different with respect to how they are 
organized, the mode of reflection and the manner in which they are written. In this analysis we will primarily focus on the intercommunicative aspect of these two blogs.

The 15-year-old English girl Alice Pyne (born 1996) created her blog in June 2011. Altogether, she made 66 blog posts until she died in January 2013. She suffered from Hodgkin's lymphoma, and after having received the diagnosis, she decided to create a wish list. This bucket list included wishes like everyone in the UK signing up as a bone marrow donor, a visit to Cadbury World, and a stay in the Chocolate room at Alton Towers. ${ }^{1}$ Alice Pyne's blog became widely known in the UK and she won the Pride of Britain Teenager of Courage award in 2012.

The Norwegian 17-years old Regine Stokke (born 1991) began blogging in august 2008 after being diagnosed with an aggressive form of leukemia. Regine Stokke frequently updated her blog with texts, photographs and some pieces of her own lyric. She posted her last blog post three days before she died in December 2009, and received more than 1784 commentaries on this unique entry. Altogether, Regine Stokke made 136 blog posts. In 2009 she was awarded "Name of the year" by one of Norway's largest newspapers. She died at the age of 18 after 15 months of illness. Her blog was published as a book in the spring of 2010 and immediately became a Norwegian bestseller. Later, the book has been translated into English (ref) and several other languages.

In the following, and illustrated with examples from Alice Pyne and Regine Stokke's' blog posts, we explore some of the ways in which intercommunication renders some basic questions of the use and function of the blog medium in general, and illness blogs in particular.

\footnotetext{
${ }^{1}$ In the 2007 film "The Bucket List" ”, two terminally ill men played by Jack Nicholson and Morgan Freeman go on a road trip with a wish list of to-dos before they "kick the bucket".
} 


\section{INTERCOMMUNICATION}

In the blogs of Alice Pyne and Regine Stokke, the comments left by the readers are most pivotal. Pyne's blog is actually organized around the response of the readers:

[M]um always tells me that life is what we make of it and so I'm going to make the best of what I have and because there were so many things I still wanted to do, mum suggested that I turn my ideas into a bucket list. [...] So, I thought it would be fun to have my list online and to tick things off and do a little update on everything I do :) If anyone has suggestions, please let mum or dad know because they don't know how to do all of it yet. They're working on it! ${ }^{12}$

In her bucket list, Alice Pyne appeals to her readers to contribute for blood marrow donors as well as for making her personal wishes come through. The blog was initiated by an appeal to the readers to come up with suggestions for her bucket list. As she starts putting the suggestions from the list into practice, she is obliged to share the planning beforehand as well as her experiences from the event. Alice Pyne's blog consists of a limited number of blog posts. The 66 entries are basically about the bucket list, and raising money for charity. Her unselfish and courageous work to build up a foundation for other sick children and promoting blood marrow donorship gave Alice Pyne national fame. Alice Pyne presents herself with extrovert character traits. She frankly tells about herself and her health condition, but without rendering much about the anxiety and pain she may have felt. This form of editing is typical of some illness stories. The need to stand out as brave, courageous and unselfish is by some scholars seen as potential pitfalls of the genre:

[C]ould it be that people facing death and disability also write in order to convince themselves and others that there is a meaning in the malady? Could it be that positive writing bolsters the morale, and that digging into the problems would lead to resignation and therefore must be avoided? And if so, does it matter? ${ }^{13}$

This may well be the case for some people writing about their illness. Beliefs and coping 
strategies are indeed individual and the way writers express their personal illness experiences and interpretations of illness should not be deemed as negative or false by critical readers as long as such individual experiences and interpretations are not being generalized in ways that may represent an additional burden to readers living with illness. For Alice Pyne and Regine Stokke, however, it seems like blogging has a therapeutic dimension as well as an explicit meaningful aspect. Neither of them reflect upon whether there is a meaning in the malady. Instead they create meaning out of it in an active approach to their everyday life with illness that may be perceived as beneficial for both themselves and others.

Another pitfall for young people blogging about serious illness may be the fact that blogging does not only render positive attention. By preparing for intercommunication, the blogger exposes herself to unknown readers, and their response is not always as positive as the blogger may expect. Despite the unselfish and charitable intentions Alice Pyne defines for her blogging, she had some negative experiences. For instance, some readers established blogs pretending to be Alice Pyne's and thereby stole the donations intended for charity. She became really upset about this: "I can't believe it! My mum just told me that some piece of poo has hacked into the Post Pal site and managed to put a PAYPAL button on there and is enjoying spending your donation to them". ${ }^{14}$ In a blogpost from June 2011 written by Alices' mother it is clear she had received some harsh anonomous comments. Alice does not comment on these herself, but her mother writes: "With regard to all the not so lovely «anon» comments been left, particularly the one asking if the bitch had die yet - you are only «anon» on this blog, you are not invincible and you ARE traceable. We will find and prosecute every one of you." This post receives 664 comments all paying tribute to Alice and her mother.

The blog of Regine Stokke is also a markedly intercommunicative one. Regine creates a dialogical arena where she asks for input about possible medical cures and for feedback on which wig to wear. Every now and then she drops a question in a small talk manner: "By the 
way, are any of you going to the Quart-festival?" She also twice initiates questions and answers sessions where her readers are free to ask of anything they like. Regine is explicit about how much the support from her readers means to her. She even entitles one of her blog posts: "An entry dedicated to my blog readers." ${ }^{15}$ Here she expresses the importance of the communication with her readers: "Every word means so much to me, and helps to keep my spirits up. I was in a pretty dark place over the holidays, and maybe I still am, but your kind words help to keep hoping. [...] Without you I could never have gotten this far!"16

However, not all of the responses to Regine's blog posts are supportive. Regine also suffers from obtrusive and insensitive response from readers, like this one from May 2010: "When will you die?" Regine is clearly upset when she answers the anonymous J:

$\mathrm{J}$ : Are you a total shithead, or what! "When will you die?" Maybe you'll die tomorrow in a car accident - you never really know. No one knows exactly when they'll die. Do you ask just so you can rub in how bad things look for me? I feel like the negative comments are getting more and more frequent, and I honestly can't understand why. ${ }^{17}$

\section{INTERCOMMUNICATION AND THE IMPLIED READER}

The insensitive comments that both Alice Pyne and Regine Stokke experience, brings forth an interesting narratological issue, namely that of the implied reader. Blogs may be characterized as digital texts, that is, texts intended for the computer. One of the peculiarities of digital texts is that they demand not only reader response, but, understood in sociological terms, reader interaction. A digital text is not fully realized until the reader has interconnected with it in one way or another. Such practice echoes the characteristics inherent in Wolfgang Isers term "the implied reader", originally developed in his famous work by the same title from 1974. The implied reader is a function of the text: 
[It] incorporates both the prestructuring of the potential meaning by the text, and the reader's actualization of this potential through the reading process. It refers to the active nature of this process - which will vary historically from one age to another - and not to a typology of possible readers. ${ }^{18}$

This interaction between author and reader is at the center of Iser's idea of the implied reader and represented a humanistic turn after Roland Barthes structuralist and anti-humanistic "death of the author". ${ }^{19}$ Iser's text was written long before blogging became a genre or even a technical possibility, and his thought may be said to have anticipated the digital evolvement that laid the premises for blogging. Yet, by emphasizing the reader, Iser stresses the text's reliance on the reader (as well as the author) to take on life. Having this notion of the implied reader in mind, the narratologist Shlomit Rimmon-Kenan's comments on the reader of illness stories is most interesting:

Writing about illness is often an attempt to share it with people who do or will suffer from the same condition and often a testimony or an appeal for empathy. The implied reader consequently has a central role for the writer. However, the specific reader may find the identification with the empathic implied reader too demanding emotionally. ${ }^{20}$

The comment made by Rimmon-Kenan is made with a traditional book-rendered illness story in mind. The implied reader is descriped as someone identifying with the author, an idea also shared by Thomas Couser in his Recovering Bodies: Illness, diability and life writing (1997) as he writes on the motivation of narrating an illness story: “[O]r merely hold hands with an imagined reader in similar distress". ${ }^{21}$ In the epilogue of his book, Couser goes on to identify three different kind of motivations for the readers of illness stories, namely that of common 
faith, sharing information and appreciating the aesthetic norms of the patography genre. ${ }^{22}$ The readers of an illness blog may be different from the readers of a book with an autobiographical illness story. The presumed homogeneity, which Rimmon-Kenan presupposes from the readers concerning their link to illness, is one of their most vital differences. Most readers of Alice Pyne and Regine Stokke's illness blogs were presumably not suffering from the same health conditions as the authors. Moreover, once these aspects of identification and contextuality are diminished, a broad specter of possible reader responses may be expected.

A further feature she identified as common to many weblogs was the use of frames $[\ldots]$ in which the author assumes that their audience shares their own background knowledge in the concepts they discuss. This supports the findings of Newsom et al. (2005) that personal weblogs have a degree of contextuality that many other genres of writing do not contain. ${ }^{23}$

Based on their reactions to insensitive responses as already exemplified, is seems likely that Alice Pyne and Regine Stokke were expecting understanding and sympathy from their readers. This is an expectation shared by most bloggers: When it comes to illness blogs the majority of readers are presumably not ill, and some are even not empathetic. Some may be driven out of pure voyeuristic interests, and some may even be teased and thrilled by others misery making them feeling more at ease with life. This may indeed be the motivation for reading a broad specter of literature. Yet when it comes to blogs, the possibility of leaving a comment makes the malicious motivation potentially more difficult. Everyone has the possibility of leaving an anonymous comment. As already discussed, this creates a possibly vulnerable situation where the ill person may be exposed to negative interaction with her real readers who differs radically from the implied reader. The notion of the implied reader thus 
seems to be important for the understanding of the function of blogs in general, and illness blogs in particular. Whereas Wolfgang Iser originally based some of the difference between the real and the implied reader on historical differences, the illness blogs stresses the existential difference: The implied reader seems to share the authors feeling of distress and anxiety, whereas the majority of real readers seem to be driven by sympathy, yet also curiosity and some even voyeuristic thrill. When it comes to blogs as digital literature the real reader is actually a participant interacting with the blogger in both reading and writing blog posts. The broad and multifaceted reader groups of illness blogs who interact with the blogger thus diminish the more homogeneous aspect originally present in Iser's phrase, and thereby vanishes some of the initial control of response made by the author.

Still, in our interpretation, both Alice Pyne and Regine Stokke found the positive implications of blogging exceeding the negative ones. In Regine's very last blog post, written three days before she passed away, she addressed her blog readers, along with her friends and family: “I'm so grateful for all the support I've gotten during this time -from family, from friends, and from my blog readers. You have no idea how much you mean to me". ${ }^{24}$ By entering into a dialogue with her readers, Regine Stokkeboth gained practical advice, the possibility to realize her own artistic potential as a photographer and poet, and she prevented a feeling of isolation. The communication with her blog readers made it possible for Regine Stokke to have an interactive social life despite her illness. Moreover, even though she did not explicitly say so, blogging may have had a therapeutic effect by easing the mental stress of being seriously ill. Research has revealed that "[...] brief structured writing sessions can significantly improve mental and physical health for some groups of people". ${ }^{25}$

Regine Stokke's and Alice Pyne's illness blogs have many similarities. Both girls are preoccupied by blood marrow donation and both report enthusiastically about things they long to do. Alice Pyne has her bucket list. Regine Stokke, who was a keen photographer is, due to 
the attention she receives through her blog, able to give a photo exhibition. However, the two blogs also differ in many respects. While Alice Pyne's blog is structured around her bucket list and her charitable work, Regine Stokke dwells more with how illness is affecting her. She involves her readers in her feeling of injustice due to her suffering. One may argue that this creates a bond and feeling of identity between Regine Stokke and her readers. Yet, we argue in line with Arthur Frank that what the dialogic form renders is not a feeling of familiarity and sameness but of deep existential difference. The communication between Regine Stokke and her readers rests on the fact that she is terminally ill and at least the majority of her readers are not. In this flux between life and death, health and illness, the fascination and creation of truth in illness blogs may be found. ${ }^{26}$

\section{PATHOGRAPHIES, EMPOWERMENT AND AGENCY}

Written autobiographical accounts of peoples' experience of illness and treatment are a type of narratives that are often called pathographies or autopathographies. ${ }^{27}{ }^{28} \mathrm{In}$ her book Reconstructing Illness. Studies in Pathographies (1999), Anne Hunsaker Hawkins discusses the concept «empowerment» emphasizing how pathographies manage to propound politically marginalized groups. Empowerment and agency are well-described processes in many sociological studies of such groups of people. The experience of illness might traditionally be considered as absolutely private, but illness and how to cope with it retains a social and cultural aspect relevant to illness narratives. ${ }^{29}$ In studies of illness narratives, Hawkins' approach to "empowerment" can be connected to the sociological concept of "agency", understood as the capacity of individuals to act independently and make their own decisions. ${ }^{30}$

Receiving and living with a cancer diagnosis as a teenager often leads to severe social and mental suffering. For long periods of time, Regine Stokke and Alice Pyne were not able to 
physically share their everyday life with friends and other young people. Young people in general are healthy, strong and often extremely focused on their education, hobbies, friends, looks and the future. To most of them, severe illness and death have not yet been part of their experience. In such a situation, youth blogs about serious illness may represent a mode of open access public self-expression and a new form of social agency. ${ }^{31}$

In her autobiographical book on the construction of cancer, Stacey states that "[d]eath confers authority upon the narrative and the narrator". ${ }^{32}$ We argue in line with Gygax (2007) that this seems to be particularly pertinent to young peoples' illness narratives that confront possible death and whose narrators may equate the writing process with living. As long as Regine Stokke and Alice Pyne are writing, they strongly signal that they are still alive and positioned in the youngsters' community via the "blogosphere". ${ }^{33}$ Narratives recounting serious illnesses often have two effects: they empower the writer on the one hand, and reassure the reader on the other. ${ }^{34}$ Blogs thus may have an empowering and therapeutic effect as "reconstruction work" where persons, positions, and experiences are defined and redefined through the autopathography. ${ }^{35}$

We link the importance of agency and empowerment in blogging as reconstruction work to the famous sociologist Aron Antonovskys' concept of "sense of coherence" and his theory of salutogenesis. ${ }^{36}{ }^{37}$ Antonovskys' perspective focuses on the postmodern need of creating selfidentity and meaning. He argues that if a person believes there is no reason to persist and confront challenges, if a person experiences no sense of meaning, he will have less motivation to cope with stress and diseases. As recognized in the blogs of Regine Stokke and Alice Pyne, serious illness reaches deep into our lives, raising questions and interpretations that move beyond scientific explanations. Illness is related to how we live our lives and how we look at 
existence and knowledge production (our epistemological position). The salutogenetic thinking focuses on man's complete history, including disease and coping resources. When people face a diagnosis, they will also seek an understanding of the existential meaning of the disease. Meaningfulness is the component considered to be the most significant because meaningfulness is motivating. It deals with the importance of being participatory and engaged in one's life and in the processes that shape one's destiny. New information or a redefinition of the situation can lead to higher comprehension and manageability, demonstrated by "empowered agents" like Regine Stokke and Alice Pyne who reconstruct and make sense of their illness and actively communicate their perspectives to significant others. Regine Stokke was asked by one of her followers about how she had been influenced by her illness. She answers this in May 2009: “I've had a lot of new life experiences. Good ones and bad ones. So I would have to say that I've gotten something out of this. I think I've become a better person». ${ }^{38}$ However, although making sense of illness like Regine Stokke does is broadly acknowledged as a possible personal and therapeutic approach to increased quality of life, it must be emphasized that such processes are deeply personal and both practically and ethically dependent on the individual patient's beliefs and motivation.

Another famous sociologist, Arthur Frank, suggests that the survivor may be called a witness due to her or his ability of being able to report from a state not reachable to anyone else. The witness formulates insights and new experiences of life that he or she shares with the reader. ${ }^{39}$ The access to some kind of threshold experience may be one of the reasons to the popularity of pathographies. Regine Stokke does neither write like an average teenager nor as a resigned cancerpatient when she formulates thoughts like these:

Waiting for death is dehumanizing. To feel your body getting worse and worse. To have to wait for answers. For the only answer that matters: Will you live or will you die? Most 
teenagers spend their time worrying about how they've done on a test, but others - like mewait to find out if they'll survive long enough to have another birthday. The world is unfair. For those of you who go on to live a long and happy life, I want you to try and give something back to the world. Think of all those other people whose lives are spent in suffering. Give. It's unbelievably important. ${ }^{40}$

Regine Stokke formulates experience-based and genuine knowledge due to her deadly disease. The disease takes life, but it also brings about a specific wisdom and general (not individual) knowledge, that Regine Stokke passes on through her blog. The knowledge she gains from her illness is a unique manifest of a terminally ill teenage girl. While teenagers are often considered superficial and egotistical, Regine Stokke demonstrates the opposite qualities.

During the last decades, sharing existential experiences in illness narratives has become a well-known source to meaning and healing. ${ }^{41}$ Based on our analysis of youth blogging about serious illness, we argue that blogging illness narratives may represent a way to agency, empowerment and creation of meaning out of a chaotic and potentially lonely situation among young people experiencing serious illness; "[t]he self of self-knowledge is the fruit of an examined life." ${ }^{42}$ The self is not fixed, but emergent or socially constructed, as it is a product of social experience and change until the day one passes away.

We argue that young people like Alice Pyne and Regine Stokke who suffer from serious illness often find themselves socially and politically marginalized. Suffering and/or recovering from cancer in public by blogging ${ }^{43}$ is in our interpretation a way for young people like Alice Pyne and Regine Stokke to voice their stories, reflections and questions in their own words. They thereby actively act as agents in youth communities. Blogging about serious 
and even fatal illness enabled Regine Stokke and Alice Pyne to gain health, social strength, and control in a technologically mediated transformation. ${ }^{44} 45$

An interesting question is whether such "agents in youth communities" may be perceived as representative for young people suffering from serious illness. We interpret Regine Stokke and Alice Pyne as outstanding, mature and verbal young women compared to others at their age, both those who suffer from serious illness and those not sharing the illness experience. Regine Stokke and Alice Pyne may thus function as agents and ideals rather than representatives for other young people. Such agents and role models are in most aspects positive contributors to experience-based knowledge about the everyday life with illness and other people's health and well-being. However, one should be aware of and respect that other young people suffering from cancer may not want to or may not have the capacities to express their situation and their needs in the same reflective and "strong" manner as Stokke and Pyne did. It is thus important that "active" and extrovert patients are understood neither as a normative patient standard nor as displaying patient behaviour that can be controlled or developed from the outside. Serious ill peoples' efforts should never be a public compulsion, both for ethical and moral reasons. ${ }^{46}$

Regine Stokke and Alice Pyne moved from "backstage" to "counterstage" 47 when they shared their illness experience in the blogosphere. ${ }^{48}$ A relevant critique of this behaviour may be that blogs exposing private experiences and perspectives can be perceived as another postmodern way of being absorbed into exhibitionism and subjectivity ${ }^{49}$, and thereby losing the capacity to use fiction for the purpose of understanding illness and suffering and writing for making order out of chaos. ${ }^{50}$

However, in our opinion youth blogging about serious illness deserves to be acknowledged and further explored as a possible valuable source Many of Regine's followers expressed that 
she inspired them, with her strength and vulnerability, and by the way she coped with her illness through the blog media. According to comments posted on her blog, Regine's openness and reflections led to learning, reflections and development in her followers. After having posted her last blog post, she received many comments of which this one is representative: "I want you to know that you've made a huge difference. You've gotten people to donate bone marrow; you've made them stop and think. You've given readers of your blog- young and old - a lot of insights into what it's like to live with terminal cancer». ${ }^{51}$ After Regine Stokke's final blog post, one of her readers, the 16-year-old girl Sara Swensson, posted a comment on the newspaper Aftenposten's youth blog "Si:D (Say It)": Through her blog posts, I got to know a strong, brave and down to earth girl, who has become a role model to me and many others...". Regines Stokke's illness blog may, from a sociological point of view, be interpreted as an empowered way of sharing her battle and her journey, expressed by herself like this in the title of her blog: "Face your fear. Accept your war. It is what it is".

\section{CONCLUDING REMARKS}

In this article we have analyzed illness blogging among young people with serious illness from both a literary and sociological perspective. By approaching the illness blogs as digital texts, we found that they realized some of the blog genre's most typical traits, namely that of intercommunication between author and reader and a flexible structure. These traits are common to all blogs, not only those based upon illness experience. By approaching the illness blogs as autopathographies, we found that they had the potential to reconstruct young cancer patients' illness experience in terms of empowerment and agency.

The threshold experience illness represents and the feeling of chaos and unpredictability present in these narratives are given a formally well suited form thanks to the blog format. By 
means of blogging, young people living with serious illness may succeed in having a social life and uphold, and even extend their social position, self-knowledge and self-esteem. The dialogical form of the blog may create a sense of identity and familiarity between reader and writer. However, the communicative aspect often rests on a premise of difference between the ill blogger and his or her healthy readers. This difference capsulated in Wolfgang Isers discussion on the difference of the implied and real reader, is very clearly illustrated when it comes to illness blogs. While most bloggers - including those writing about their own illness - tend to address someone like themselves, the readers, however, seems to be more heterogeneous something which may be reflected in the comments they leave.

We argue that youth blogging may represent a fruitful strategy for some young people living with serious illness to create meaning, stay front-stage in youth communities and build selfesteem and confidence out of chaos. Furthermore, we argue that such blogs may contribute rather unique experience-based knowledge and reflections about existential issues to blog readers. Thus, blogging in general, and the illness blogs in particular, should be acknowledged and further explored as a valuable source to interaction and writing in the future. 


\section{REFERENCES}

${ }^{1}$ Iyengar, S. Shakespeare's Medical Language: A Dictionary. London: Arden 2011

${ }^{2}$ Shakespeare, W. Julius Caesar. New York: Harper \& Brothers 1843[1599]: 251

${ }^{3}$ McCosker, A. Blogging Illness: Recovering in Public. M/C Journal 2008; 11(6): 1266

${ }^{4}$ Heilferty, CM. Toward a theory of online communication in illness: concept analysis of illness blogs". Journal of advanced Nursing, 2009 Jul;65(7):1539-47. doi: 10.1111/j.13652648.2009

${ }^{5}$ Mortensen, T. and Walker J. Blogging thoughts: personal publication as an online research tool Morrison, A ed Researching ICTs in Context, Oslo:InterMedia Report 2002;3.

${ }^{6}$ Gill, AJ, Nowson S and Oberlander, J. What are they blogging about? Personality, Topic and Motivation in Blogs. Proceedings of the Third International ICWSM Conference, 2009:18

${ }^{7}$ Heilferty, CM Toward a theory of online communication in illness: concept analysis of illness blogs. Journal of advanced Nursing 2009;7:1539-47. doi: 10.1111/j.1365-2648.2009

${ }^{8}$ Herring, S. et al Weblogs as a bridging genre. Information Technology and People 2006;2:142-171.

${ }^{9}$ Schmidt, J. Blogging Practices: An analytical Framework. Journal of Computer Mediated Communication 2007;12:1409-1427.

${ }^{10}$ Herring, S. et al Weblogs as a bridging genre. Information Technology and People 2006;2:142-171.

${ }^{11}$ Nardi, A.B. et al Blogging as Social Activity, or Would You Let 900 Million People read Your Diary? CSCW 04 Proceedings of the 2004 ACM conference on Computer supported cooperative work 2004:222-231.

12 Pyne, A. Alice Pyne's Bucket List. http://alicepyne.blogspot.no/ Entry 060611. Read 150415)

${ }^{13}$ Frich, J. and Holmøy, T. Death brings me closer to life. In: Dietrichs E, and Stien R eds.

The Brain and the Arts. Oslo: Koloritt 2008:165

${ }^{14}$ Pyne, A. Alice Pyne's Bucket List. http://alicepyne.blogspot.no/ Entry 190611. Read 150415.

${ }^{15}$ Stokke, R. Regine's Book. A teen girl's last words. Oslo: Gyldendal, 2012:104

${ }^{16}$ Stokke, R. Regine's Book. A teen girl's last words. Oslo: Gyldendal, 2012:105

${ }^{17}$ Stokke, R. Regine's Book. A teen girl's last words. Oslo: Gyldendal, 2012:135

${ }^{18}$ Iser, W The Implied Reader. Patterns of Communication in Prose Fiction from Bunyan to Beckett Baltimore: Johns Hopkins, 1974:xii

${ }^{19}$ Barthes, R. Image-Music-Text. New York: Hill and Wang 1977.

${ }^{20}$ Rimmon-Kenan, S What can narrative theory learn from illness narratives? Literature and Medicine 2006;2:241-254.

${ }^{21}$ Couser, T. Recovering Bodies. Illness, diability and life writing. The University of Wisconsin Press 1997: XI

${ }^{22}$ Couser, Thomas. Recovering Bodies. Illness, diability and life writing. The University of Wisconsin Press 1997: 293

${ }^{23}$ Gill, AJ, Nowson S. and Oberlander, J. What are they blogging about? Personality, Topic and Motivation in Blogs. Proceedings of the Third International ICWSM Conference 2009:19

${ }^{24}$ Stokke, R. Regine's Book. A teen girl's last words. Oslo: Gyldendal 2012:287

${ }^{25}$ Singer, J. and Singer GHS. Writing as Physical and Emotional Healing: Findings from Clinical Research. Handbook of Research on Writing: History, Society, School, Individual, Text. Ed. Charles Bazerman C. ed. New York: Lawrence Erlbaum Associates, 2008:485-498.

${ }^{26}$ Frank AW. Illness and Autobiographical Work: Dialogue as Narrative Destabilization. Qualitative Sociology 2000:1 
${ }^{27}$ Frank, AW. The wounded Storyteller. Chicago and London: University of Chicago Press 1995.

${ }^{28}$ Hawkins, AH. Reconstructing Illness : Studies in Pathography. West Lafayette, Indiana:Purdue University Press 1999.

${ }^{29}$ McCosker, A Blogging Illness: Recovering in Public M/C Journal 2008;11:6.

${ }^{30}$ Barker, C. Cultural studies: Theory and practice. London: Sage Publications 2005.

${ }^{31}$ Lovink, Geert Zero Comments: Blogging and Critical Internet Culture. London, Routledge $\varnothing$ 2008.

${ }^{32}$ Stacey, Jackie Teratologies: A Cultural Study of Cancer. London and New

York: Routledge 1997:243

${ }^{33}$ Schmidt, J Blogging Practices: An analytical Framework. Journal of Computer Mediated Communication 2007;12:1409-1427

${ }^{34}$ Gygax, F The aesthetics of illness : narratives as

Empowerment. SPELL: Swiss papers in English papers in English language and literature 2007;20:191-206 http://dx.doi.org/10.5169/seals-100067 (published Online first:

35 (Frank, 1995; Hawkins, 1999)

${ }^{36}$ Antonovsky, A. Health, stress, and coping. San Francisco: Jossey-Bass 1979.

${ }^{37}$ Antonovsky, Aron. Unraveling the mystery of health: How people manage stress and stay well. San Francisco: Jossey-Bass 1987.

${ }^{38}$ Stokke, R. Regine's Book. A teen girl's last words. Oslo: Gyldendal, 2012: 160

${ }^{39}$ Frank, AW. The wounded Storyteller. Chicago and London: University of Chicago Press 1995

${ }^{40}$ Stokke, R. Regine's Book. A teen girl's last words. Oslo: Gyldendal 2012:111

${ }^{41}$ Hawkins, AH. Reconstructing Illness: Studies in Pathography. West Lafayette, Indiana:Purdue University Press 1999.

${ }^{42}$ Ricoeur, P. Time and Narrative. Vol. III. Trans. Kathleen Blarney and David Pellauer. Chicago and London: University of Chicago Press 1988:247

${ }^{43}$ McCosker, A. Blogging Illness: Recovering in Public M/C Journal 2008; 11

${ }^{44}$ London, R. et al The Role of Community Technology Centers in Youth Skill-Building and Empowerment 2006.

${ }^{45}$ Radsch, C. \& Khamis, S. In Their Own Voice: Technologically mediated empowerment and transformation among young Arab women. Feminist Media Studies 2013:5

${ }^{46}$ Salamonsen, A. Use of Complementary and Alternative Medicine in Patients with Cancer or Multiple Sclerosis: Possible Public Health Implications. European Journal of Public Health 2015; E-pub ahead of print. doi:10.1093/eurpub/ckv184

${ }^{47}$ Goffman, E. The Presentation of Self in Everyday Life. Garden City N.Y:Doubleday 1959

${ }^{48}$ Schmidt, J. Blogging Practices: An analytical Framework. Journal of Computer Mediated Communication 2007;12:1409-1427

${ }^{49}$ de Laat, PB. Online diaries: Reflections on Trust, Privacy, and Exhibitionism. Ethics and Information Technology 2008:10:57-69

${ }^{50}$ Bolton, G. Poetry as a key for healthcare. In: Evans, M. and Finlay, I. eds. Medical

Humanities. London: BKJ Books 2001:129.

${ }^{51}$ Stokke, R. Regine's Book. A teen girl's last words. Oslo: Gyldendal 2012:293 